\title{
AS FORMAS ELEMENTARES DA VIDA RELIGIOSA E AS CIÊNCIAS SOCIAIS CONTEMPORÂNEAS*
}

Renato Ortiz

De que modo abordar a problemática das ciências sociais contemporâneas tendo como referência uma obra específica de Durkheim? Uma alternativa, que iremos descartar, seria encontrar o caminho da influência de Durkheim e de seu livro junto a autores relevantes de nossa tradição intelectual. Dentro dessa perspectiva, teríamos que analisar seus escritos buscando entender em que medida a abordagem durkheimiana contribuiu para a elaboração dos objetos de estudo desses autores. Por exemplo, que lugar ocupa As formas elementares da vida religiosa no pensamento de Radcliffe-Brown ou Talcot Parsons e, no caso brasileiro, de alguém como Florestan Fernandes? Porém, como as ciências sociais desenvolveram-se em contextos nacionais, deveríamos considerar outros elementos: a concepção da escola francesa na qual a antropologia e a sociologia faziam parte da mesma totalidade; a perspectiva anglo-saxônica que divi-

\footnotetext{
Conferência de abertura do colóquio internacional sobre os cem anos de publicação de As formas elementares da vida religiosa, realizado em São Luís, Universidade Federal do Maranhão, em junho de 2012.
} 
de a herança durkheimiana entre sociólogos e antropólogos. No Brasil, apesar do vínculo inicial com o pensamento oriundo da França (recordo as aulas sobre Durkheim dadas por Roger Bastide na Universidade de São Paulo), predominou uma concepção norte-americana na qual $A$ divisão do trabalho social, As regras do método sociológico e $O$ suicídio tornaram-se prerrogativas dos sociólogos, enquanto os estudos sobre a religião ficaram reservados ao domínio dos antropólogos. Talvez por isso, sendo tardia a institucionalização das ciências sociais brasileiras, a tradução de As formas elementares para o português somente veio à luz em 1989, quando em espanhol ela data de muito antes (uma tradução foi publicada na Argentina em 1968).

No entanto, prefiro seguir outra direção e construir meu raciocínio a partir de uma indagação: o que o leitor contemporâneo pode retirar de um livro como As formas elementares da vida religiosa $a^{1}$ ? Esta é uma pergunta interessada 14 e, em certa medida, parcial, pois não visa analisar detalhadamente o texto do autor, mas sim privilegiar um olhar retrospectivo imerso no presente. Mas é possível justificá-la. É importante distinguir nas ciências sociais o datado do ultrapassado. Não tenho dúvida de que, em determinados aspectos, nossa compreensão do funcionamento das sociedades humanas avançou. Sabemos hoje muito mais sobre a Grécia Antiga do que nossos antepassados, e também sobre temas como imigração, racismo e etnocentrismo. Entretanto, contrariamente à física ou à biologia, as ciências sociais são fundamentalmente interpretativas e não acumulam informações e conhecimento da mesma maneira que aquelas. "Datado" significa vinculado a determinado contexto, por exemplo: a reflexão sobre a modernidade industrial é datada porque toma como objeto uma configuração social

\footnotetext{
${ }^{1}$ Foi dentro dessa mesma perspectiva que trabalhei o texto sobre a atualidade do pensamento de Antonio Gramsci. Ver Ortiz (2006a).
} 
inscrita no espaço - alguns países europeus - e no tempo - o século XIX. Nesse sentido, todo trabalho intelectual é datado, ele dialoga com a contemporaneidade que, ao longo da história, se desfaz. Posto isso, retomar um clássico da sociologia seria um anacronismo? Penso que não. Nossos clássicos são datados, mas a eles não se aplica inteiramente a noção de superação. Pode-se lê-los ou relê-los a partir do presente e sob óticas diferentes, e este é o exercício que me proponho a realizar com As formas elementares. Um primeiro aspecto a ser destacado diz respeito à dificuldade do texto. Cabe lembrar que seus interlocutores são, em boa parte, antropólogos britânicos, já que depois da fundação do L'Année Sociologique, que privilegiava estudos de caráter antropológico, o vínculo entre o grupo durkheimiano e os ingleses se reforçou. A religião, os ritos, os costumes folclóricos - enfim, a tradição - tornam-se temas importantes para o desenvolvimento do pensamento sociológico na França. Quando Durkheim justifica a mudança de rumo de suas pesquisas (ele se refere ao curso sobre religião dado em 1895), é justamente um autor de língua inglesa que ele retém: Robert $\mathrm{Smith}^{2}$. Não se pode esquecer Marcel Mauss, que durante a Primeira Grande Guerra atuou como tradutor junto aos soldados britânicos e fez seu "rito intelectual de passagem" nas universidades inglesas (Fournier, 1994). Porém, os autores que fornecem o material etnográfico a partir do qual Durkheim refletiu são desconhecidos para nós, leitores contemporâneos. Torna-se assim difícil acompanhar o emaranhado dos exemplos utilizados ao longo do livro. O mesmo é possível ser dito em relação ao público britânico ou australiano atual, ele também faz parte de um

\footnotetext{
${ }^{2}$ Seu testemunho é sugestivo: "Até 1895 não consegui ter uma ideia clara do papel essencial que desempenhava a religião na vida social. Foi neste ano, pela primeira vez, que encontrei a maneira de abordar sociologicamente o estudo da religião. Foi para mim uma revelação. O curso de 1895 supõe uma linha divisória no desenvolvimento de meu pensamento".
} 
"nós" que se distanciou do passado. É importante ter em mente que os trabalhos utilizados no livro fazem parte de uma herança "pré-científica" da antropologia britânica. Eles são anteriores aos estudos dos pais fundadores Malinowski ou Radcliffe-Brown. As novas gerações de antropólogos, a não ser quando voltadas para a história das ideias, tem pouca ou nenhuma familiaridade com esses escritos. Outro aspecto diz respeito ao objeto de estudo, a saber, os aborígenes australianos: eles já não mais existem no contexto trabalhado pela etnografia da época. Seus rituais, hábitos, mitos, modos tecnológicos, transformaram-se radicalmente. Esses grupos étnicos tampouco desfrutam do estatuto que lhes era conferido no final do século XIX, quando eram vistos como representantes dos "primitivos", momento que a observação participante os considerava informantes privilegiados do passado longínquo da humanidade. Hoje, eles podem ser considerados atores políticos dinâmicos, participativos, que leem 16 os antropólogos, inclusive para os contestarem.

Mas qual é o lugar de As formas elementares entre os escritos de Durkheim? Um ponto sublinhado por diversos autores refere-se à mudança de rumo do pensamento do autor ${ }^{3}$. Em seus primeiros escritos, ele procurava compreender os fenômenos sociais a partir da base morfológica da sociedade, o que explica seu interesse pelas noções de volume e densidade. Por exemplo, em A divisão do trabalho social, ele afirma que a divisão do trabalho varia com relação direta à densidade e ao volume das sociedades. Esta é uma abordagem que já se encontra na sua tese escrita em latim sobre a contribuição de Montesquieu para as ciências sociais (Durkheim, 1966). A leitura que ele faz de $O$ espírito das leis é a de que Montesquieu não teria simplesmente considerado as diversas formas de organização política de acordo com as diferentes sociedades, ele teria "deduzido" tais formas de orga-

${ }^{3}$ Um texto um tanto esquecido que aborda esse aspecto é Gurvitch (1950). 
nização da morfologia dessas sociedades. Assim, a república seria uma característica das cidades pequenas, com uma densidade populacional média; enquanto que o governo despótico seria específico às sociedades cuja população está espalhada por um vasto território geográfico (por exemplo, os impérios). A forma de governo, vinculada à densidade populacional de um determinado lugar, seria uma variável da base morfológica de cada sociedade. Esta é a concepção que norteia o estudo sobre a divisão do trabalho e, em função dela, Durkheim critica a perspectiva de Foustel de Coulanges sobre a relação entre religião e sociedade. Para ele, seu antigo professor e autor de $A$ cidade antiga teria se equivocado ao dizer que a organização e a constituição da família primitiva teria por base a religião. Seria justamente o contrário, Foustel de Coulanges teria tomado a causa pelo efeito. Isto é, fez a sociedade derivar da religião quando deveríamos considerar o inverso, as formas sociais antecederiam e influenciariam diretamente os modos religiosos. Em As formas elementares, esse ponto de vista será reformulado. Tem-se agora a primazia da consciência coletiva sobre a morfologia social. Por isso ele dirá: "a consciência coletiva é muito mais que um epifenômeno da base morfológica” (Durkheim, 1968, p. 695). Durkheim passa, assim, a se interessar pelo domínio da "superestrutura", ou seja, dos símbolos, tema que destacarei em seguida. Outra dimensão da obra durkheimiana refere-se às noções de consciência coletiva, solidariedade mecânica e orgânica. Em A divisão do trabalho social, a consciência coletiva encontrava-se associada à ideia de solidariedade mecânica, sendo um vínculo específico das sociedades "primitivas", nas quais a individualidade de seus integrantes tenderia a zero. O todo social mecanicamente se reproduziria no comportamento das pessoas. Com a progressão histórica e o advento, nas sociedades complexas, de outro tipo de dinâmica social, que privilegia a solidariedade orgânica, a consciência coletiva tenderia a 
desaparecer. Já em O suicídio, essa concepção sofre algumas mudanças, pois o suicídio egoísta pressupõe justamente o afastamento do indivíduo da consciência coletiva que uniria os membros de um grupo determinado. Um exemplo: se os católicos se suicidam menos do que os protestantes, isso se dá porque o grau de coesão daquele grupo é maior e entre os protestantes a individuação da relação entre deus e o homem levaria a um enfraquecimento dos vínculos coletivos. No caso de As formas elementares, a noção se precisa abarcando a própria ideia de religião. Nesse sentido, não existiria mais a oposição entre mecânico e orgânico (Durkheim abandona a ideia de solidariedade mecânica): as sociedades indígenas surgem na sua complexidade e o estudo dos universos religiosos serviria de parâmetro para a compreensão do vínculo social nas sociedades modernas.

Por fim, é importante recordar certos pontos críticos da obra de Durkheim que diversos intérpretes também subli18 nharam. Alguns deles são de cunho etnográfico e dizem respeito à base empírica do material utilizado, o qual correspondia, como apontei no início, ao conhecimento acumulado na época a uma fase ainda preliminar da disciplina antropologia. As pesquisas anteriores irão rever e muitas vezes invalidar diversos argumentos apresentados nos trabalhos desses precursores do pensamento antropológico. O próprio objeto escolhido por Durkheim, o totemismo, é colocado em causa, por ser considerado um tipo de organização atípica e que dificilmente poderia servir de base para a generalização de suas conclusões. Na verdade, a ideia de que o totemismo constituiria um sistema, como pensava Frazer, cai por terra; cada vez mais se percebe que por trás dessa denominação comum existia um conjunto de fenômenos distintos. Lévi-Strauss (1974) dirá que nos encontrávamos diante da história de uma ilusão que pouco a pouco se desfaz. Restam ainda os problemas de natureza teórica. A busca pelo nascimento da religião é um deles, esta é uma obsessão 
do século XIX quando a questão das origens do homem dominava ainda o pensamento sociológico. Durkheim "des-constrói” de maneira inteligente as premissas do animismo de Tylor ao recusar buscar a origem da religião na confusão mental inicial entre o estado de vigília e o sonho. Essa perspectiva nos levaria a pensar que os universos religiosos derivariam de simples alucinações. A desconfiança durkheimiana da interpretação do naturismo de Max Müller é também sugestiva (nos primeiros capítulos do livro faz-se uma revisão crítica das principais teorias a respeito da origem da religião). No entanto, Durkheim cai na mesma armadilha dos autores que comenta, ao encontrar a causa da religião na efervescência dos fenômenos da multidão. Os dados etnográficos indicavam que a vida dos povos australianos passava alternativamente por duas fases distintas: num primeiro momento, a população indígena encontrava-se dispersa sobre um vasto território e dedicava-se a atividades corriqueiras como a coleta de grãos, a pesca e a caça; no outro, excepcional, os clãs agrupavam-se numa multidão de indivíduos na qual vivia-se um período de intensa efervescência coletiva. Durkheim associa esses dois estágios à dicotomia profano/sagrado, mas dá um passo além ao dizer: "[...] é nesse meio social efervescente e desta própria efervescência que parece ter nascido a ideia religiosa" (1968, p. 313). Tese que se alicerça numa inversão lógica. Afinal, se os grupos australianos reuniam-se excepcionalmente para celebrar seus ritos coletivos, isso se dava por que a religião devia previamente existir, ela seria a "causa" da efervescência e não o efeito (para utilizarmos um jargão do século XIX). Outro problema vincula-se à noção de religião elementar. Durkheim utiliza o termo primitivo num duplo sentido, o de selvagem (reforçando o etnocentrismo europeu) e o de primeiro (os povos que teriam antecedido a todos os outros na escala evolutiva dos homens). Para o autor, a religião dos australianos seria a mais simples possível, ou seja, 
a mais fácil de se entender sociologicamente e que conteria o "elemento" estrutural anterior a toda religião. As formas elementares da vida religiosa expressariam assim o universal inerente a qualquer tipo de fenômeno religioso. Pode-se, então, entender o argumento utilizado pelo autor: "uma lei que foi demonstrada por uma experiência benfeita é válida universalmente". Ao decompor a existência de uma fase elementar da vida religiosa teríamos, em princípio, descoberto a chave de entendimento de todas as expressões religiosas, independentemente de suas formas históricas (o que é uma ilusão). Pressupõe-se dessa maneira que as ciências sociais teriam a capacidade de descobrir leis universais e não históricas dos arranjos sociais, o que entra em contradição com as lições de As regras do método sociológico, quando Durkheim nos dizia que o método comparativo era o único recurso teórico disponível para o sociólogo fazer generalizações.

Quais seriam os pontos do livro que desafiam a ima20 ginação sociológica do leitor contemporâneo? Eu diria, antes de tudo, a importância da dimensão simbólica. Ela pode ser apreendida por meio da noção de sagrado que Durkheim desenvolve em alguns artigos publicados em L'Année Sociologique (por exemplo: "Nature et fonction du sacré”) e que se precisa em As formas elementares. Parto de uma afirmação preliminar: o sagrado é algo que se acrescenta, se sobrepõe ao real; trata-se de uma realidade de segunda ordem. Uma interpretação possível é considerá-lo dentro de uma perspectiva restrita aos universos religiosos, ou seja, a oposição sagrado e profano nos remeteria exclusivamente ao tema da religião, como é o caso do totem. Durkheim dirá: ele é um nome, isto é, um artifício de denominação das coisas que nos cercam. Cada clã define um grupo social por meio de um nome específico como sol, lua, estrela, trovão etc. Ele é também um emblema, um ícone que se materializa e permite a identificação das pessoas a um mesmo segmento social ("o totem é o emblema 
da tribo"). Assim o clã e, no interior dele, cada família, adota um animal ou um vegetal como brasão totêmico, mas suas propriedades não se resumem a isso: o totem é sagrado; a ele associam-se qualidades inexistentes nos objetos profanos. Por isso ele deve ser isolado das coisas comuns, ser piedosamente conservado em lugares especiais, exprimindo um estado excepcional da dimensão social. Para Durkheim, o sagrado e o profano são duas qualidades opostas, heterogêneas e constituem uma dicotomia mais profunda do que a separação entre o bem e o mal, espécies contrárias do mesmo gênero: o sagrado possui uma natureza inteiramente distinta do profano, como se fossem construídos de matérias incompatíveis. Daí a necessidade de conservá-lo ao abrigo da vida ordinária. Trata-se de dois mundos incongruentes, aptos, porém, a se comunicarem entre si. Os ritos empreendidos cuidadosamente pelos especialistas teriam a função de mediar a aproximação desses polos antagônicos. No entanto, os objetos nos quais o sagrado se incrusta são banais, um animal, um vegetal, um pedaço de madeira. Ele tem, portanto, a capacidade de se "sobrepor ao profano" ao lhe conferir um valor antes desconhecido. As coisas triviais sofrem um processo de transmutação simbólica e adquirem outra essência. Uma pedra, um rio, uma árvore, um animal deixam de ser parte integrante do ambiente físico e social para se constituírem em objetos marcados pela sua potência, que lhes acrescenta um grau diferenciado de significado.

Entretanto, essa discussão não se confina à temática da religião, e o próprio autor chama a atenção para isso. $\mathrm{Na}$ conclusão de seu livro, ele faz uma série de digressões sobre a problemática do simbólico, evidenciando seu interesse pela faculdade de idealização que todo ser humano possui ao ser capaz de "substituir ao mundo da realidade um mundo diferente no qual ele se transporta pelo pensamento". Perguntando-se sobre a natureza dessa faculdade, ele 
responde: "A explicação que propusemos sobre a religião tem precisamente esta vantagem de dar uma resposta a esta pergunta. Pois o que define o sagrado é que ele se acrescenta ao real. Uma sociedade não pode criar ou se recriar sem ao mesmo tempo criar um ideal. Essa criação não é para ela um ato suregatório, por meio do qual ela se completaria uma vez formada; este é um ato através do qual ela se refaz periodicamente"(1968, pp. 602-3). A passagem merece alguns comentários, sobretudo, para evitar mal-entendidos. O termo ideal não é empregado no sentido de perfeição, de excelência, tampouco se associa a idealismo ou a ideário, conjunto de ideias de uma doutrina. Ele nomeia uma virtude específica do ser humano: a capacidade de simbolização. A religião ensina a Durkheim que o sagrado esconde um mecanismo inerente a toda atividade humana. "Sobrepor-se ao real" significa que não podemos apreendê-lo sem que algo seja "acrescentado" à materialidade do próprio real.

22 A vida social inexiste sem o mecanismo da representação simbólica, essa "realidade de segunda ordem" é constitutiva do que denominamos sociedade. O raciocínio apresentado é semelhante ao dos linguistas quando abordam a língua como uma faculdade do ser humano. Para Saussure, por exemplo, o signo tem dupla dimensão: o significante, sua materialidade, e o significado, aquilo ao que ele remete. A realidade somente pode ser percebida por meio dessa dupla articulação entre a materialidade e a representação que dela fazemos. Desse modo, não nos encontramos nunca diante de um objeto primeiro, a experiência inicial é sempre mediada pelo signo. Durkheim dirá que esse labor de significação constitui um "primeiro fundo de representações" relativamente autônomas; elas irão em seguida se "atrair", se "repelir" e, enfim, formar "sínteses de todas as espécies", constituindo a consciência coletiva na qual se inserem as pessoas (cf. Durkheim, 1951). Se as representações simbólicas não se confinam ao domínio da religião, sendo cons- 
titutivas da vida em sociedade, o espaço da cultura passa a ter um papel crucial na articulação e na compreensão das relações sociais. Curiosamente, foi este o motivo de várias críticas, pertinentes, na época, em relação à escola francesa de sociologia. Ao privilegiar a esfera do simbólico, ela teria deixado de lado outras dimensões da sociedade: Estado, partidos políticos, classes sociais (mesmo um autor como Halbwachs, uma exceção entre os durkheimianos, que se ocupa da temática das classes, tem interesse limitado pela ideia de conflito). Assim, a problemática do poder encontraria pouco espaço para se manifestar (embora um autor como Georges Balandier (1969) perceba que a análise do sagrado nas sociedades indígenas seja "uma das dimensões do campo político”). Isso é válido inclusive para o tema da religião. Enquanto Weber toma como um dos eixos principais de suas análises a dominação (a Igreja é uma empresa de salvação das almas), nos escritos durkheimianos, sublinha-se o elemento da coesão social, a religião como sistema solidário de práticas e crenças. Entretanto, para o leitor contemporâneo, diante do conjunto de transformações ocorridas ao longo do século XX, o domínio da cultura toma outra configuração. A questão do poder, que não mais se identifica exclusivamente com a política, passa em grande medida ao largo das instituições tradicionais que a abrigavam: partido, sindicato, Estado. Dito de outra maneira, ela se inscreve na cultura (reconhecimento, identidades, direitos culturais, etnicidade, questões de gênero etc.). Nesse sentido, a releitura de um texto como As formas elementares é sugestiva, pois nos permite trabalhar o domínio do simbólico articulando-o às hierarquias e às relações de poder.

Durkheim (1968) também nos remete ao problema das classificações do pensamento - que já aparecera em Durkheim e Mauss (1903) e que Herz (1970) desdobrará - o qual é trabalhado ao longo de todo o livro. A crítica contida nessa obra é a de que as categorias do conhecimento 
são sociais e não inatas, universais, contrariamente ao que imaginava Kant. Cada sociedade secretaria formas distintas de apreensão do mundo. Para ser mais preciso, elas não seriam apenas diferentes em suas concepções de mundo (seus conteúdos), cada universo simbólico se organizaria por meio de categorias de pensamento específicas. Por exemplo, a noção de espaço: longe de ser um traço universal do "espírito humano", ela adquire uma feição particular em cada sociedade. Lançam-se assim as bases de uma sociologia do conhecimento, o que torna plausível falarmos do conceito de espaço dos aborígenes australianos, dos gregos antigos ou das pessoas na Idade Média europeia. Mas as categorias de pensamento, ao recortarem a realidade, introduzem no âmbito do social dois outros princípios: diferenciação e hierarquização. Por exemplo, Durkheim e Mauss mostram como os Zuñis (do norte do México) organizam espacialmente seu mundo: ao Norte, associam o vento, o inverno, 24 o pelicano, o carvalho verde e amarelo, a força e a guerra; ao Oeste, a água, a primavera, o urso, o azul, a paz e a caça (Durkheim e Mauss, 1969). Cada ponto cardinal congrega elementos da natureza, animais, coisas e funções sociais: agricultura, magia, religião e guerra. $\mathrm{O}$ universo natural e humano torna-se inteligível por meio dessas categorias: Norte, Sul, Leste, Oeste, zênite e nadir. Elas estabelecem um padrão de diferenciação capaz de agrupar as qualidades sociais e individuais em classes diferentes. Mas Durkheim acrescenta: a oposição entre sagrado e profano não apenas distingue as coisas entre si, mas o que se encontra classificado ao lado do sagrado possui um valor superior ao que se associa ao profano. Nesse sentido, direita e esquerda não seriam simplesmente classificações espaciais, elas encerrariam uma escala de valores. A direita nos remete às noções de ordem, alto, centro, masculino, correção; a esquerda, à desordem, baixo, margem, feminino, desvio. Assim, quando algumas sociedades classificam a família e a aldeia como 
pertencentes ao polo da ordem, do masculino, elas também sugerem que outras dimensões como o imoral, o estrangeiro e o feminino, sejam atributos do polo da desordem. As categorias de classificação antecedem assim os conteúdos do pensamento, elas constituem as formas por meio das quais eles são ordenados e hierarquizados. Vários trabalhos em antropologia irão explorar essa dimensão inaugurada pela escola francesa e talvez um dos mais expressivos seja $O$ pensamento selvagem, de Lévi-Strauss. No entanto, elas não se limitam ao estudo das sociedades ditas tradicionais. Pierre Bourdieu, por exemplo, procura desenvolvê-la em relação às práticas sociais e culturais. A distinção trabalha justamente este aspecto: como as classificações reforçam a conivência entre as pessoas, reproduzindo relações de poder inscritas na sociedade como um todo. Existiria assim uma disputa simbólica em torno dessas categorias, pois se trata de entender "quem" possui a capacidade de defini-las como legítimas: distinguir "arte" de "não arte", "verdadeiro" de "falso" etc.:

A discretio classificatória fixa, da mesma forma que o direito, um estado de relação de forças que ela visa eternizar pela explicação e pela codificação. O princípio de divisão lógica e política do sistema de classificação somente possui existência e eficácia porque ele reproduz, de forma transfigurada, a lógica simbólica dos desníveis diferenciais (Bourdieu, 1979, p. 559).

Nesse sentido, as reflexões de Durkheim são um ponto de partida interessante para compreendermos, inclusive, algumas questões da contemporaneidade. Retiro um exemplo de minhas próprias pesquisas (Ortiz, 2006b). Para considerar alguns aspectos da problemática da mundialização da cultura, constituí um corpo de textos escritos por homens de negócios, administradores de empresa, escritores de best 
sellers, artigos de revistas como a Harvard Business Review, com o objetivo de ter disponível um material empírico específico e analisar um discurso que "populariza" a temática da globalização. Minha intenção era captar como se estruturava o que denominei de senso comum planetário. Apesar da variedade dos conteúdos dos textos, assim como das perspectivas analíticas, foi possível agrupar os argumentos dos autores em dois eixos: um temporal, outro formado por pares de oposição (as classificações que nos interessam). No eixo temporal, repousa um pressuposto: o mundo global seria inteiramente distinto do mundo pré-global. Existiria uma ruptura histórica entre diferentes "eras" (postulado encontrado também na literatura pós-moderna). Já os pares de oposição formam os subentendidos estruturantes do pensamento. Centralização/descentralização, padronização/segmentação, homogeneidade/heterogeneidade, enrijecimento/flexibilidade. Essas antinomias podem 26 ser articuladas entre si, sem que estejam num primeiro momento relacionadas ao eixo temporal. Isso permite construir um conjunto de afirmações do tipo: "a padronização requer um tipo de organização centralizadora"; "a flexibilidade das novas tecnologias favorece a descentralização"; "o mundo industrial era homogêneo e enrijecido”. O conteúdo de cada uma dessas frases articula os elementos das antinomias anteriores: padronização e centralização, flexibilidade e descentralização, homogeneidade e enrijecimento. Mas esses pares de oposição podem ainda, articulando-se agora ao eixo temporal, associarem-se a outros: totalitarismo/ democracia, massa/indivíduo, coerção/liberdade, material/imaterial. Isso amplia o arco de formação de sentenças: "o totalitarismo da era industrial fundamentava-se na existência de um único padrão para todos"; "a descentralização do mercado promove a liberdade individual"; "o fim da cultura de massa implica a desmaterialização dos bens culturais"; "numa economia flexível não existem mais bens 
tangíveis"; "o computador, instrumento de uma era flexível, é mais democrático e plural do que a televisão”. Não me importa discutir o conteúdo de cada uma dessas frases (há muito de ideológico nelas). O relevante é compreender que os termos centralização, padronização, sociedade de massa, totalitarismo pertenceriam a uma fase ultrapassada do mundo pré-global; que as qualidades positivas, descentralização, flexibilidade, imaterialidade, liberdade de escolha, seriam imanentes ao momento posterior de globalização. A legitimidade das sentenças se instaura quando as categorias de classificação do pensamento se naturalizam, quando são aceitas acriticamente. Elas são convincentes não apenas pelo que enunciam de modo explícito, mas, sobretudo, por que as categorias "invisíveis" que estruturam o discurso são tacitamente compartilhadas pelos membros da mesma comunidade discursiva.

Sublinho ainda um último aspecto relativo à minha leitura interessada: o tema da tradição. Durkheim tem sido considerado por alguns intérpretes um pensador conservador. Na América Latina, particularmente nos anos de 1960, esse tipo de visão generalizou-se entre os autores marxistas e os sociólogos voltados para a problemática da modernização e da mudança social. Creio que o livro de Robert Nisbet The sociological tradition, publicado em 1966 e traduzido para o espanhol em 1969, contribuiu em muito para isso ${ }^{4}$. Ele não hesita em rotular Durkheim como um representante do conservadorismo político e social. Pode-se evidentemente questionar seu ponto de vista lembrando que esta não é a imagem de que a escola durkheimiana desfruta entre os franceses. Durkheim é um intelectual profundamente vinculado à III República, forma de governo que substitui a tradição conservadora que imperava

\footnotetext{
${ }^{4} \mathrm{O}$ título em espanhol do livro de Nisbet é La formación del pensamiento sociológico [A formação do pensamento sociológico].
} 
na França desde a derrota de Napoleão em 1815. Vários membros de sua equipe de trabalho partilhavam um ideário de esquerda, Mauss e Halbwachs eram, respectivamente, socialista e comunista ativos. São inúmeros os textos que demonstram como o nascimento das ciências sociais francesas encontra-se intimamente articulado às transformações do final do século XIX, em especial à emergência da universidade moderna e à defesa do ensino laico (Weiz, 1979). Inclusive, o engajamento de Durkheim nas questões políticas de sua época será tema de controvérsias posteriores, mas sem lhe atribuir uma dimensão conservadora. Durkheim é criticado na primeira metade do século XX porque personagens como Sartre ou Paul Nizan o consideram um "intelectual orgânico" da III República, uma manifestação da consciência burguesa. No entanto, não me interessa tanto questionar a afirmação anterior, este não é o foco de minha argumentação. Importa compreender os 28 motivos que levaram Nisbet a tal conclusão. Essa leitura de Durkheim é a de um liberal norte-americano. Ele considera que a ênfase no individualismo do século XVIII, que se insurgiu contra o passado medieval, cede lugar no XIX a uma rebelião contra esse próprio individualismo. O conservadorismo consistiria numa perspectiva anti-iluminista e na valorização da tradição e da ordem. Nisbet argumenta ainda que, muitas vezes, alguns autores partilhavam, no campo da política e da economia, alguns elementos do ideário liberal, no entanto, estes vinham marcados por um "conservadorismo conceitual". No século XIX, os liberais mantiveram a convicção, herdada do Iluminismo, de que o progresso residia na emancipação da mente e do espírito humanos. Durkheim se afasta dessa ideia progressista e progressiva da história, colocando-se no lado oposto ao de Marx ou de Condorcet; sua preocupação excessiva com os laços sociais (religião e memória) e comunitários, solidariedade mecânica ou orgânica, o deixaria à margem 
das correntes intelectuais que privilegiavam a mudança, a utopia ou a revolução diante da preservação do passado. Por isso, ele é visto como alguém que cultiva certo pessimismo em relação ao progresso material e social inaugurado pela revolução industrial. De fato, Durkheim desconfia da noção de progresso e, se nos primeiros escritos, ele ainda a considera relevante, ao analisar a progressão da divisão do trabalho, seu interesse pelas sociedades ágrafas o distanciará cada vez mais das premissas dessa noção. Contudo, ao situarmos sua obra em nossa contemporaneidade, salta aos olhos o fato de ser justamente esse elemento de crítica que se torna problemático. Para nós, houve um declínio da ideologia do progresso, ela já não é mais, para falarmos como Lyotard, um “grande relato”. É sempre possível aplicá-la ao domínio da técnica, quando se considera o desempenho de determinado aparato diante de outros julgados ultrapassados, mas ela não mais possui a capacidade de articular as diversas dimensões da vida social: arte, sociedade, economia, moral, ética. O progresso econômico e tecnológico não caminha em paralelo ao desenvolvimento da justiça, da moral ou da política. A flecha do tempo se quebrou, é impossível ordenar as sociedades e os povos num contínuo temporal homogêneo. Isso significa que a oposição tradicional/moderno, constitutiva do pensamento sociológico, possui hoje pouca eficácia epistemológica, ou seja, poder de convencimento. Esses termos, antes antagônicos, podem se combinar de diversas maneiras e, o que é mais importante, eles deixam de existir no singular para se manifestarem no plural: fala-se em modernidades-múltiplas e tradições. Dentro desse contexto, o tema da tradição é inteiramente resignificado, ressurgindo no debate contemporâneo associado à problemática da diversidade, das identidades e das questões étnicas. A releitura de um clássico que a ele confere um lugar de destaque é interessante, ela nos permite apreender o presente, em certa medida, devo sublinhar, 
com outros olhos. Mas é possível dizer mais. A tradição não é simplesmente o testemunho do passado, algo que persiste, ou uma sobrevivência; ela é também representação. Este é o caso de algumas comunidades indígenas ou grupos populares (quilombolas, entre outros), que na construção de suas identidades apreendem e reinventam o passado, na qual o presente atua, como filtro de uma memória coletiva apagada pelo tempo. Um exemplo sugestivo é a categoria de "povos originários", que passa a dominar a esfera pública e a política nacional num país como a Bolívia. À primeira vista, poderíamos dizer que se trata das populações que viviam na América Latina antes da colonização espanhola. Mas o termo não é sinônimo de nativo ou de aborígene; "povos originários" constitui uma expressão trabalhada pelos intelectuais orgânicos indígenas na qual a trajetória subalterna de um grupo social manifesta-se no interior da história boliviana. Ela denota um conjunto de indivídu30 os que se autoidentifica e se legitima na cena pública em contraposição a outros interesses políticos e ideológicos. A tradição é, dessa forma, "preservada" e "deformada". Sua preservação nos remete à materialidade dos fatos: o idioma quéchua ou aimará, os costumes, vestimentas, formas de cultivar a terra etc. Mas eles não são em si suficientes, é necessário que o trabalho simbólico os reinterprete conferindo-lhes uma consistência que não possuíam antes. Dito em termos durkheimianos: a tradição é simultaneamente fato social e representação.

\section{Renato Ortiz}

é professor titular do departamento de sociologia do IFCH/ Unicamp.

\section{Referências bibliográficas}

BALANDIER, G. 1969. Antropologia política. São Paulo: Difel/Edusp. BOURDIEU, P. 1979. La distinction. Paris: Minuit. 
DURKHEIM, E. 1951. "Répresentations individuelles et représentations collectives”. In: Sociologie et philosophie. Paris: PUF. 1966. Montesquieu et Rousseau: précurseurs de la sociologie. Paris: Macel Rivière. 1968. Les formes élémentaires de la vie religieuse. Paris: PUF. ; MAUSS, M. 1903. "De quelques formes primitives de classification: contribuition à l'étude des représentations collectives”. L'Année Sociologique (1901-1902), n.6, pp.1-72.

FOURNIER, M. 1994. Marcel Mauss. Paris: Fayard.

GURVITCH, G. 1950. "La sociologie en profondeur". In: La vocation actuelle de la sociologie. Paris: PUF.

HERTZ, R. 1970. "La prééminence de la main droite: étude sur la polarité religieuse". In: Sociologie religieuse et folklore. Paris: PUF.

LÉVI-STRAUSS, C. 1974. Le totemisme aujourd'hui. Paris: PUF.

NISBET, R. 1966. The sociological tradition. New York: Basic Books.

ORTIZ, R. 2006a. "Notas sobre Gramsci e as ciências sociais". Revista Brasileira de Ciências Sociais, v.21, n.62, pp.95-103.

2006b. "O senso comum planetário". In: Mundialização: saberes e crenças. São Paulo: Brasiliense.

WEIZ, G. 1979. "L’idéologie républicaine et les sciences sociales". Revue Française de Sociologie, v.XX, n.1, pp.83-112. 


\section{AS FORMAS ELEMENTARES DA VIDA RELIGIOSA E AS CIÊNCIAS SOCIAIS CONTEMPORÂNEAS}

RENATO ORTIZ

Resumo: A partir da questão "como abordar a problemática das ciências sociais contemporâneas tendo como referência a obra específica de um autor?", o artigo examina As formas elementares da vida religiosa de Émile Durkheim. Recusa a alternativa de recuperar sua influência junto a uma série de intelectuais relevantes na área e segue outra direção - a saber, a de indagar o que o leitor contemporâneo pode retirar desse texto - na qual privilegia um olhar retrospectivo imerso no presente, pois, em relação ao momento da escritura daquela obra, a compreensão do funcionamento das sociedades humanas avançou. Mostra que a discussão sobre o sagrado não se confina à temática da religião, ao lembrar que, na conclusão do livro sob exame, Durkheim faz uma série de digressões acerca da problemática do simbólico. Esses símbolos, indispensáveis à criação e recriação das sociedades, são retomados no desenvolvimento deste texto.

Palavras-chave: Émile Durkheim; As Formas Elementares da Vida Religiosa; Sagrado e Profano; Simbólico; Recriação Social.

\section{THE ELEMENTARY FORMS OF THE RELIGIOUS LIFE AND THE CONTEMPORARY SOCIAL SCIENCES}

Abstract: Beginning from the question "how to address the problems of the contemporary social sciences taking a specific work of an author as reference?", this article examines The elementary forms of religious life by Émile Durkheim. It refuses the alternative of regain his influence on relevant intellectuals in the area, and goes in another direction - namely, to inquire what the contemporary reader can obtain from that work - in which a retrospective look, immersed in the present, is privileged, because, in relation to the time in which this book was written, progressed the comprehension 
of how work the human societies. It shows that the discussion about the sacred is not confined to the topic of religion, to remember that, at the conclusion of the book under review, Durkheim makes a series of digressions about the problematic of symbolic. These symbols, which are necessary for the social creation and recreation, are incorporated on the development of this article.

Keywords: Émile Durkheim, The Elementary Forms of Religious Life, Sacred and Profane; Symbolic; Social Recreation.

Recebido: 01/08/2012 Aprovado: 29/08/2012 